\title{
Short-term memory: Effects of acoustic similarity, presentation rate and presentation mode'
}

\author{
KENMETH R. LAUGHERY AND ALLEN L, PINKUS \\ STATE UNIVERSITY OF NEW YORK AT BUFFALO
}

The effects of four variables on short-term memory were studied: Presentation Rate (20,60 or 180 items/min.), Presentation Mode (visual or auditory), Acoustic Similarity (High, BCDEGPTVZ or Low, HJLOQRWXY), and Length of Sequence (6 or 8 items). Performance varied inversely with the Length of Sequence and Acoustic Similarity and directly with Presentation Rate. A significant Presentation Rate by Presentation Mode interaction was explained on the basis of less available time for rehearsal at the fast presentation rate due to the time required for the implicit translation from visual input to the storage of auditory cues.

The importance of auditory encoding in short-term memory (STM) has been demonstrated in several studies. Conrad (1964) and Wickelgren (1965a) have shown that intrusion errors in STM tend to have a vowel or consonant sound in common with the correct item. Other studies, Laughery (1963), Sperling (1963), Conrad \& Hull (1964), and Wickelgren (1965b) indicate that sequences of acoustically distinct letters are better recalled than sequences of acoustically similar letters.

On the basis of the evidence to date, it appears that auditory cues are the most crucial for retrieval from STM. For example, the effects of acoustic similarity have been shown to be greater than the equivalent effects of semantic similarity (Baddeley, in press). This argument, however, does not preclude retrieval from STM based upon other cues such as visual or kinesthetic (Hintzman, 1965). If dimensions other than auditory can serve as cues for retrieval, it should be possible to demonstrate a lesser effect of acoustic similarity under conditions where auditory cues are less likely to be available.

One factor that may influence the availability of auditory cues is presentation rate. The argument here is that a slower presentation rate leads to more implicit rehearsal between items. According to Sperling (1963), this rehearsal is essentially auditory; that is, a review of the auditory cues. Thus, if the presentation rate is fast enough to preclude rehearsal, the availability of auditory cues should be minimized. Conrad, Baddeley, \& Hull (1966) have recently studied the acoustic similarity effect under two conditions of presentation rate: 60 and $120 \mathrm{items} / \mathrm{min}$. The results showed the effect of acoustic similarity to be highly significant, while neither the effect of rate nor the interaction was significant. It should be noted, however, that their fastest rate does not necessarily preclude rehearsal. Previous work by Pollack (1952) as well as some unreported data from our own laboratory indicate that rehearsal does occur at this rate. Thus, a faster rate may be necessary.

Mode of presentation is a second factor that may in- fluence the availability of auditory cues. It seems reasonable to assume that a visual presentation is likely to result in a lesser availability of auditory cues than an auditory presentation. This difference should be a factor at the faster presentation rates since less time is available for the implicit translation from visual to auditory cues which are later used in retrieval.

The present study is designed to test the hypothesis that the effect of acoustic similarity on STM will be less at a faster presentation rate when the mode of presentation is visual.

Method

Ss were 120 students from an Introductory Psychology course at the State University of New York at Buffalo.

Four variables were manipulated in the present experiment. Presentation Rate was included as a between Ss variable and consisted of 20,60 or 180 items $/ \mathrm{min}$. Presentation Mode, also manipulated as a between Ss variable, consisted of a visual or auditory presentation. Acoustic Similarity was manipulated as a between Ss variable and consisted of sequences composed of high similarity letters (B, C, D, E, G, P, T, V and Z) or low similarity letters ( $H, J, L, O, Q, R . W, X$ and $Y) . A$ fourth variable, Length of Sequence, was manipulated as a within Ss variable and included sequences of six or eight items.

The visual presentation was made on an in-line digital display unit where the letter was a lighted item on a dark background. The presentation of the letters was controlled by a network of Grason-Stadler Electronic Control Modules. At the 180 items $/ \mathrm{min}$. presentation rate the items were in the visual field for the full $1 / 3$ $\mathrm{sec}$. For the 60 and 20 items $/ \mathrm{min}$. rates, the items were in the visual field for $1 / 2 \mathrm{sec}$, and the field was blank during the remainder of the inter-item interval. This procedure was introduced to equate the visual presentation on-time to the pronunciation time of the items in the auditory mode.

Ss were run in pairs and were seated at regular classroom type desks in a small room. In the visual mode of presentation they faced the in-line digital display unit which was located approximately five feet from the S's eyes. In the auditory mode of presentation, the speaker through which the information was presented was located in the same position as the display unit in the visual mode. Ten Ss were run in each of the 12 treatment groups. Each $\mathrm{S}$ was exposed to 11 sequences of each length-a total of 22 sequences. Approximately half the Ss in each group received the six item sequences followed by the eight item sequences while the remaining half in each group received the eight item sequences 
Table 1. Mean number of item errors per sequence

\begin{tabular}{|c|c|c|c|c|}
\hline & & & 6 items & 8 items \\
\hline \multirow{5}{*}{180 items/min. } & \multirow{2}{*}{ Visual } & Low Sim & 1.78 & 4.09 \\
\hline & & High Sim & 2.68 & 4.74 \\
\hline & & & & \\
\hline & \multirow{2}{*}{ Auditory } & Low Sim & 0.43 & 2.52 \\
\hline & & High Sim & 1.87 & 4.15 \\
\hline \multirow{5}{*}{$60 \mathrm{item} \mathrm{s} / \mathrm{min}$} & \multirow{2}{*}{ Visual } & Low Sim & 0.80 & 2.81 \\
\hline & & High Sim & 1.91 & 4.28 \\
\hline & & & & \\
\hline & \multirow{2}{*}{ Auditory } & Low Sim & 0.85 & 2.81 \\
\hline & & High Sim & 2.22 & 3.96 \\
\hline \multirow{5}{*}{$20 \mathrm{items} / \mathrm{min}$} & \multirow{2}{*}{ Visual } & Low Sim & 0.42 & 1.90 \\
\hline & & High Sim & 0.42 & 1.90 \\
\hline & \multirow{3}{*}{ Auditory } & & & \\
\hline & & Low Sim & 0.51 & 1.95 \\
\hline & & High Sim & 1.01 & 2.29 \\
\hline
\end{tabular}

first. The Ss responded by writing down the sequences with each item in its appropriate position. In other words, the Ss were instructed to try to put the first item they heard in the first position, the lastitem in the last position, and so forth. They were encouraged to guess. The Ss were also informed as to the set of items from which the sequences would be drawn and the set was displayed at the top of the answer sheets. Sequences were made up by randomly drawing items from the symbol set with the restriction that no item could appear more than once in a sequence.

Results

Total number item errors summed over the last 10 trials were used as a measure of performance. An item was considered wrong unless it was correctly reproduced in the proper position. Table 1 presents the mean number of item errors per sequence for each of the experimental conditions. An analysis of variance showed the main effects of the four variables to be significant: Length of Sequence, $F=377.68, \mathrm{df}=1 / 108, \mathrm{p}<.001$; Presentation Rate, $F=24.17$, df $=2 / 108, p<.001$; Presentation Mode, $F=6.80, \mathrm{df}=1 / 108, \mathrm{p}<.025$; and Acoustic Similarity, $F=43.36, \mathrm{df}=1 / 108, \mathrm{p}<.001$. Performance varied directly with presentation rate, inversely with length of sequence and acoustic similarity, and was superior in the auditory mode.

The Presentation Rate by Length of Sequence interaction was significant, $F=5.49, \mathrm{df}=2 / 108, \mathrm{p}<.01$, with the effect of rate being greater for the longer sequences.

The Presentation Rate by Presentation Mode interaction was also significant, $F=4.83, \mathrm{df}=2 / 108, \mathrm{p}<.01$. The data underlying this interaction indicate that at the 60 and 20 items $/ \mathrm{min}$. rates there is no difference between visual and auditory; whereas, performance is superior for auditory at the $180 \mathrm{items} / \mathrm{min}$. rate.

\section{Discussion}

The main effects of Length of Sequence, Presentation Rate and Acoustic Similarity are consistent with previous findings on STM. The Presentation Rate by Length of Sequence interaction can probably best be explained in terms of rehearsal. At the faster rates there is less opportinity for rehearsal, and more errors accumulate in the longer sequences than at the slower rates where rehearsal permits more items to be retained. The shorter sequences, however, contain few enough items so that they are not lost from memory even at the faster rates.

The effect of Presentation Mode can best be considered within the context of the Presentation Rate by Presentation Mode interaction. If auditory cues are most crucial for retrieval from STM, then it is reasonable to find no mode effect at the slower presentation rates. At slower rates there is ample opportunity for transforming visual input into auditory-acoustical storage. At the faster rates, however, there would be less time available for the translation from visual to auditory, resulting in the storage of fewer auditory cues and hence poorer performance.

While the above argument may provide an explanation for the Presentation Rate by Presentation Mode interaction, it would also predict a significant triple interaction: Presentation Rate by Presentation Mode by Acoustical Similarity. If the fast presentation rate precludes the transformation from visual input to auditory storage, the effects of acoustic similarity should be absent in this condition. This prediction was indeed the hypothesis that led to the present experiment and was not confirmed by the results.

An alternative explanation is that the $180 \mathrm{items} / \mathrm{min}$. rate is sufficient for the translation to occur from visual input to the storage of auditory cues, but that this translation requires processing time, which, in turn, is not available for other processes such as rehearsal. Thus, the auditory cues are available for retrieval in the visual presentation mode, resulting in the significant effect of acoustic similarity in this condition. Performance is poorer in this condition, however, since less time is available for rehearsal.

\section{References}

Baddeley, A. D. Short-term memory for word sequences as a function of acoustic, semantic and formal similarity. Quart. J. exp. Psychol., in press.

Conrad, R. Acoustic confusion in immediate memory. Brit. J. Psychol., 1964, 55, 75-84.

Conrad, R., Baddeley, A. D., \& Hull, A. J. Rate of presentation and the acoustic similarity effect in short-term memory. Psychon. Sci., 1966, 5, 233-234.

Conrad, R., \& Hull, A. J. Information, acoustic confusion and memory span. Brit. J.. Psychol., 1964, 55, 429-432.

Hintzman, D. L. Classification and aural coding in short-term memory. Psychon. Sci.,1965, 3, 161-162.

Laughery, K. R. Effects of symbol set on immediate memory. Amer. Psychologist, 1963, 18, 415 (Abstract).

Pollack, I. The assimilation of sequentially encoded information: II. Effect of rate of information presentation. USAF ARDC Hum. Resourc. Lab. memo. Rep., 1952, No. 25.

Sperling, G. A. A model for visual memory tasks. Hum. Factors, $1963,5,19-31$.

Wickelgren, W. A. Acoustic similarity and intrusion errors in shortterm memory. J. exp. Psycho: h., 1965a, 70, 102-108.

Wickelgren, W. A. Short-term memory for phonemically similar Note lists. Amer. J. Psychol., 1965b, 78, 567-574.

1. Supported by $\mathrm{MH}-11595$. 